\title{
Predication analysis of English possessive sentences
}

\author{
Viatcheslav Yatsko, Tatiana Yatsko (Abakan)
}

\begin{abstract}
The paper focuses on distribution and correlation of semantic features distinguished within scope of predication analysis, viz. causative, agentive, inchoative, egressive, continuative, and stative features. Causative possessive constructions are taken to be basic while the other ones are derived from them by omission of appropriate semantic features. The structure of causative possessive sentences is described in terms of componential analysis.
\end{abstract}

\section{$1 \quad$ Introduction}

In contemporary linguistics possession is regarded as one of the main categories investigated in a significant number of works. Summarizing their contents we distinguish the following specific features of the linguistic category of possession.

1. Possession represents relationship between two entities, manifested by the schematic structure $X$ POSS $Y$, where $X$ and $Y$ are nominal expressions referred to as "possessor" and "possessee" (or "possessum") (Taylor 2001: 2; McGregor 2009). The semantics of possessive constructions involves referential characteristics of the possessor, the possessee and the possessive relation holding between them (Storto $2003: 2$ ).

2. The essential feature of the possessive relation is control that possessor $(X)$ exercises over possessee $(Y)$. Looking at everyday definitions of possession we find that Merriam-Webster Online Dictionary (2008) gives the following interpretation:

1) a: the act of having or taking into control; b: control or occupancy of property without regard to ownership c: ownership; d: control of the ball or puck; also: an instance of having such control (as in football); 2) something owned, occupied, or controlled: property.

Christian Lehmann (2002: 7) notes that control of the possessum by the possessor is the default assumption and insofar the default interpretation of the possessive relation.

Such an interpretation excludes from the present analysis sentences, in which $X$ and $Y$ are non-human, see (1) below, as well as sentences expressing family relations: *Nichols has a brother, but he is not a twin. ${ }^{1}$ According to a broader approach possession is treated as a relational concept that covers relations between persons and their body parts and products, between persons and their kin, between persons and their material belongings, between persons and things they control over, etc. (McGregor $2009: 1$ ).

\footnotetext{
1 All examples marked with an asterisk are taken from The Corpus of Contemporary American English (COCA), http://corpus.byu.edu/coca/ (accessed December 5, 2013). The examples marked with ** are taken from The British National Corpus, http://corpus.byu.edu/bnc/ (accessed December 5, 2013). Examples that are unmarked (three of them) have been construed for the purposes of present analysis.
} 
3. In English the category of possession is manifested on different levels of language system. On the morphological level it is realized by the 's (*the Winchester rifle is Alison's); on the lexical level it is expressed by means of possessive verbs, nouns, pronouns, and adjectives with possessive meaning (own, possess, property); on the syntactic level it is expressed by noun phrases (*They hear a HORN HONKING, and turn just as Ben 's car comes flying past them) and predicative constructions, in which the possessive relation is lexicalized in possessive verbs, e.g. *Her mother used to drive her everywhere, and now Alyssa has a car.

According to the way of expressing the category of possession on the syntactic level languages are divided into Habeo-languages having special possessive verbs, which take a direct object, and Esso-languages, which have no possessive verbs, and in which the idea of possession is expressed by the constructions with the verb to be (cf. Seiler 1983). English is a typical Habeo-language since it has a number of possessive verbs.

Peter Willemse, Kristine Davidse and Liesbet Heyvaert (2009) argue that proper interpretation of possessum's referent requires analysis of discourse context in which corresponding NPs occur thus adding a discourse dimension to the study of the category of possession.

This paper will concentrate on predicative possessive constructions.

4. Linguistic investigations of the category of possession have been focused on developing the taxonomy of possessive constructions, characterization of their types and subtypes. John R. Taylor (2001: 6) provides evidence that the first such taxonomy was created by H. Poutsma in the work dated as early as 1914. Since that time a number of taxonomies have been created that take into account semantic, syntactic, and pragmatic characteristics of $X, Y$ and POSS. As we showed earlier (cf. Yatsko/Yatsko 2012) the taxonomies have been developed within scopes of two approaches. The taxonomic approach is based on the principle of a univocal correspondence between the linguistic form and content: any construction that contains lexical and grammatical manifestations of possession is considered possessive. The restrictive approach holds that lexical and grammatical possessive markers can express not only possessive meaning but also other types of meaning such as existence or location.

For example (1) within scope of the taxonomic approach will be regarded as a possessive sentence (since it features the possessive marker has) while according to the restrictive approach being possessive in form it is existential by its nature. \\ *The house has several bedrooms}

Existential semantics of (1) can be revealed by application of interrogation test, cf:: Are there bedrooms in the house? - Yes, the house has several bedrooms. Existential nature of the sentence is clearly indicated by There + be construction. Other tests used to detect the semantics of possessive constructions include transposition of $X$ and $Y$; substitution; insertion; deletion; transformation of predicative constructions into non-predicative and vice versa. These tests correspond to those ones used in transformational grammar as constituency tests. (cf. Börjars/Burridge 2001 : 24-33)

Another assumption underlying the restrictive approach is that possessive semantics can vary in its intensity, in some contexts it can be completely or partially neutralized. 
The aim of this paper is to suggest a novel approach to classification of possessive sentences based on predication analysis methodology. We will focus on the analysis of causative sentences that, in our opinion, are prototypical to the domain of alienable possession ${ }^{2}$ and reveal some factors that influence the intensity of possessive semantics and determine its gradational character.

\section{Predication analysis}

The term "predication analysis" was introduced by Laurel Brinton (2000: 276-287). Depending on the distribution of semantic features of predicates Brinton distinguishes between stative, inchoative, continuative, egressive, causative, and agentive sentences. Stative predicates and sentences denote an unchanging condition whereas inchoative sentences denote a change in state or the beginning of a new state. Causative sentences denote something effecting a change of state in an entity, and agentive sentences involve a human agent who intentionally and volitionally brings about a change in state in an entity. The end or cessation of a state is termed egressive while continuative sentences express a continuation of a state.

Stative predicates and sentences are assumed to be basic, being analyzed with the stative feature BE; other types of sentences are formed by adding additional semantic features. In inchoative sentences the predicates are analyzed with the stative feature plus an additional inchoative feature COME; causative sentences are distinguished by the additional feature CAUSE while the nature of agentive sentences can be represented by the agentive feature DO. Egressive and continuative predicates can be analyzed with COME NEG and NEG COME NEG features (id.: 277-281).

Brinton's predication analysis is evidently based on the ideas earlier formulated by David Dowty (1979) who distinguished between DO, BECOME, CAUSE operators to describe the meaning of four verb classes expressing state, achievement, activity, and accomplishment. Adding two more features BE and NEG allows getting six main predicate types and six contaminated types thus making up a powerful and flexible methodology for the explanation and description of predicative constructions.

We think that Brinton's conception can be best explained in terms of distributional analysis.

Contrastive distribution characterizes predicates with opposite meanings, stative - inchoative, causative - agentive. A sentence cannot be stative and inchoative at the same time. Such features as inchoative and causative, inchoative and agentive, egressive and causative, egressive and agentive, continuative and causative, continuative and agentive are in complementary distribution and can occur in one and the same sentence to make up contaminated forms. Table 1 represents distribution of semantic features of predicates. + denotes features that are in contrastive distribution; - is used to describe features that are in complementary distribution, and 0 stands for inapplicable variants.

\footnotetext{
2 The semantic field of possession is traditionally divided into alienable and inalienable possession. As Brinton notes "there are two kinds of possession depending on whether the possessor and the thing possessed are inherently connected .. or not" (Brinton 2000: 268); see also Carranza (2010: 149).
} 


\begin{tabular}{|l|c|c|c|c|c|c|}
\hline $\begin{array}{l}\text { Semantic } \\
\text { features }\end{array}$ & Stative & Inchoative & Causative & Agentive & Egressive & Continuative \\
\hline Stative & 0 & + & 0 & 0 & 0 & 0 \\
\hline Inchoative & + & 0 & - & - & 0 & 0 \\
\hline Causative & 0 & - & 0 & + & - & - \\
\hline Agentive & 0 & - & + & 0 & - & - \\
\hline Egressive & 0 & 0 & - & - & 0 & + \\
\hline Continuative & 0 & 0 & - & - & + & 0 \\
\hline
\end{tabular}

Table 1. The distribution of semantic features of predicates

Brinton's conception, being sound and well substantiated, cannot be directly extrapolated to the analysis of possessive sentences and needs to be modified. The main problem that arises here is interpretation of causative sentences. In Brinton's opinion they involve 2-place predicates with a Force role and a Patient role, for example The heat dried the clothes. (cf. Brinton 2000: 278) Since the Force role denotes an inanimate object this interpretation obviously contradicts our approach adopted earlier, according to which a prototypical possessor is human. More appropriate for the purposes of this research will be another understanding of the causative semantic feature described in a number of works (see, e. g. Lehmann 1991; Premper 1991: 11; Dixon 2000: 62-77; Comrie 1981: 163-167) according to which prototypical causativity involves two agents, causator and causee, the main difference between them being in the degree of control. Causator acts naturally, intentionally, and directly while the causee either lacks control or has control but is willing and is only partially affected. This understanding of causative constructions can be illustrated by the following examples.

(2.1) *The soldiers marched toward the sound and smoke of battle

(2.2) *Nothstein's mother marched the boys...

(3) John caused Mary to break her cup

(4) John made Mary do her home assignments

(5) *Kim bought that car from Robert

(6) The thieves robbed the passengers of their money

In (4) the causator (John) exerts full control over the situation acting intentionally and volitionally and the causee's (Mary) volition and intention is neutralized; she is not willing and performs the action under compulsion. In (3) it's not clear whether the causator's action was intentional or unintentional. More prototypical situation is that his actions are unintentional (John stumbled, jogged Mary and caused her to break her cup). In (2.2) the causator acts intentionally and volitionally while the causees' intention is neutralized and volition partially neutralized because they may be willing to perform the action. In (2.1) the causator is not mentioned and this sentence is not causative. The difference between (2.2) and (3)-(4) is that in the latter the causative component is lexicalized in the separate verb and in 
the former it is integrated with the lexical meaning of the verb predicate. The possessive sentence (6) shares characteristics with (4), the causator fully controls the situation whereas the causee is unintentional and non-volitional. The structure of (5) is more complex because both participants (denoted as Kim and Robert) are volitional and intentional, to reveal difference between them we need an additional semantic component, viz. initiator since one of the participants (Kim) acts as an initiator of the situation.

As we mentioned earlier the generally accepted point of view holds that the structure of possessive constructions has three components, $\mathrm{X}$ (possessor), Y, (possessee) and POSS. But (5) and (6) feature an additional nominal component denoting the person who (volitionally as in (5) or non-volitionally as in (6)) loses possession of $Y$. We will term this component possessor 2 and designate it as $X_{2}$ to distinguish from $X_{1}$, the initiator of the situation. This situation may be described as transference of $Y$ from one person to the other one. We consider this situation to be prototypical for English possessive sentences basing on the notion of the prototypical situation (Kleiber 1990 : 10; Rosch 1975, 1978: 27), according to which it can be interpreted as a mental scheme that appears in human brain on perception of a linguistic sign. Mental scheme invoked on perception of possessive verb buy comprises the three participants mentioned above, and the possessive verbs in English causative sentences may be defined as 3-place predicates. The other types of possessive predicates are 2-place. We think that being prototypical causative sentences are basic and the other types of possessive predicative constructions are derived from them by means of omission of a semantic feature. Agentive predicative constructions are derived from causative ones by omission of CAUSE feature; inchoative constructions are formed by omission of DO feature; stative constructions are produced due to omission of COME feature. Table 2 represents our view of the paradigm of English possessive predicative constructions.

\begin{tabular}{|c|c|c|c|}
\hline \multicolumn{2}{|c|}{ Construction type } & Scheme & Example \\
\hline \multirow[b]{3}{*}{ 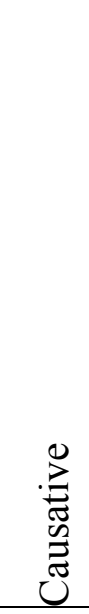 } & Causative-inchoative & $\begin{array}{l}\mathrm{X}_{1} \text { DO CAUSE } \quad \mathrm{X}_{2} \\
\text { COME HAVE Y }\end{array}$ & $\begin{array}{l}\text { *..she left the house to John and } \\
\text { his sister. }\end{array}$ \\
\hline & Causative-egressive & $\begin{array}{l}\mathrm{X}_{2} \text { DO CAUSE } \mathrm{X}_{1} \\
\text { COME NEG HAVE Y }\end{array}$ & $\begin{array}{l}\text { * A person robbed a pedestrian of } \\
\text { money at gunpoint, then fled. }\end{array}$ \\
\hline & Causative-continuative & $\begin{array}{l}X_{1} \text { DO CAUSE } X_{2} \\
\text { NEG COME NEG } \\
\text { HAVE Y }\end{array}$ & - \\
\hline \multirow[b]{2}{*}{ 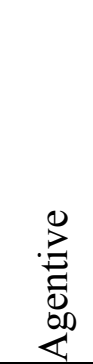 } & Agentive-inchoative & $\begin{array}{l}\text { X DO COME HAVE } \\
Y\end{array}$ & $\begin{array}{l}\text { * He received a gold medal for } \\
\text { My House in Winter of about } \\
1911 \text {. }\end{array}$ \\
\hline & Agentive-egressive & $\begin{array}{l}X \text { DO COME NEG } \\
\text { HAVE Y }\end{array}$ & * I have sold the shop.. \\
\hline
\end{tabular}




\begin{tabular}{|c|c|c|}
\hline Agentive continuative & $\begin{array}{l}X \text { DO NEG COME } \\
\text { NEG HAVE Y }\end{array}$ & $\begin{array}{l}\text { *..he was keeping the } 56 \text { Club } \\
\text { Libby Lu stores. }\end{array}$ \\
\hline Inchoative & X COME HAVE Y & $\begin{array}{l}\text { *..My father inherited the chicken } \\
\text { farm. }\end{array}$ \\
\hline Egressive & $\begin{array}{l}\text { X COME NEG HAVE } \\
Y\end{array}$ & * We lost our house. \\
\hline Continuative & $\begin{array}{l}X \text { NEG COME NEG } \\
\text { HAVE Y }\end{array}$ & $\begin{array}{l}\text { *..her father remained in } \\
\text { possession of Gordon Glen. }\end{array}$ \\
\hline Stative & X HAVE Y & *..they own a gun. \\
\hline
\end{tabular}

Table 2. The paradigm of English predicative possessive constructions

We failed to find any examples of the causative-continuative sentences in COCA as well as in BNC. We can conjecture that the meaning of such sentences ( $X_{1}$ causes $X_{2}$ to lose $Y$ but $X_{2}$ remains in possession of $Y^{\prime}$ ) contradicts the prototypical situation that implies transference of $Y$ from one possessor to the other one. The other types of causative possessive sentences are described in the next section of the paper.

\section{Causative possessive sentences}

In contrast with continuative-causative constructions egressive-causative and inchoativecausative sentences are widespread in English since their meaning corresponds to the structure of the prototypical situation.

Causative-egressive sentences imply $X_{1}$ 's actions aimed at getting $Y$ from $X_{2}$ to become its new possessor. The most typical (and prototypical) sentences are characterized by the concrete reference of $X_{1}$ and $X_{2}$ and direct contact between them. This semantics is realized by the verb rob of. In (7) the names of $X_{1}$ (men) and $X_{2}$ (women) have reference to specific persons, which is manifested by attributes (two masked) and specific date. The name of $Y$ (jewelry) indicates direct contact between $X_{1}$ and $X_{2}$.

(7) *"Two women reported Aug. 13 they were at a car wash and two masked men robbed them of their jewelry."

The egressive semantics may decrease in case 1) the name of $X_{2}$ acquires indefinite reference, 2) $X_{2}$ refers to a group of people, 3) the name of $Y$ is not mentioned, 4) the possessive verb denotes a repeated action. In (8.3) and (9.6) $Y$ is not mentioned, $X_{2}$ is denoted by collective nouns (the federal government, a lot of people), the verb rob from is used in the Past Simple to denote a repeated action. Actually these sentences are used to substantiate conclusions about qualities of persons. (8.3) provides evidence about Sheriff Billy McGee being a hero and (9.6) contributes to the negative characteristics of the personage. In both sentences $X_{l}$ is not presented as a new possessor and the idea of transference of possessee from one possessor to the other one is not expressed. 
(8.1) *Sheriff Billy McGee is a local hero in Hattiesburg, Mississippi.

(8.2) His story, a modern twist on Robinhood.

(8.3) He robbed from the federal government to give to the needy in his county.

(9.1) *How dare she - how dare she spend time at the movies by herself?

(9.2) People were sitting around losing sleep, thinking that on these days she was suffering, she was going through chemotherapy, throwing up.

(9.3) And meanwhile, she was at the tanning salon.

(9.4) At the tanning salon!

(9.5) She took advantage of everybody that surrounds her, and not just financial, but emotionally.

(9.6) "And she robbed from a lot of people."

The use of collective nouns to denote $X_{2}$ implies absence of contact between $X_{1}$ and $X_{2}$.

The most typical causative-egressive verb that presumes lack of contact between $X_{1}$ and $X_{2}$ is steal, cf. the dictionary definition "to take (something) from someone, etc. without permission or unlawfully, esp in a secret manner" (Collins English Dictionary and Tesaurus 1992). Sentences with steal demonstrate the same distribution of gradational semantics as those one with rob. Causative-egressive semantics is prototypically expressed in the sentences with $X_{1}$, $X_{2}$ and $Y$ that have concrete reference to specific objects. Sentence (10) evidently denotes a unique situation, all components referring specific objects.

(10) *There was a party the night Clyde stole the mercury from Mel's Pharmacy. (Roberge, Rob 1999)

In (11) the name of $Y$ (a fortune) has an indefinite reference, which decreases egressive semantics. The speaker tries to show that the theft didn't take place.

(11) **Baroness Susan De Stempel, who's now been released, claims the police forced her to admit she stole a fortune from her senile aunt.

In (12) the egressive semantics is further decreased by the use of $Y$ with indefinite reference (What we owned) and collective nouns (the merchants, the lawyers) to denote $X_{2}$; the indefiniteness of reference is intensified by the substantivized adjectives the fat and the rich. The sentence is used to justify $\mathrm{X}_{1}$ 's actions rather than to express the idea of transference of property.

(12) **What we owned we stole and filched, not from the poor but the merchants, the lawyers, the fat and the rich.

Causative-inchoative sentences denote the situation in which $X_{2}$ comes into possession of $Y$ thanks to intentional and volitional efforts of $X_{l}$. The most widely used inchoative-causative verb is buy, the use of which implies, as we noted earlier, volitional and intentional actions on the part of $X_{2}$ as well. Unlike egressive-causative verbs causative-inchoative ones cannot be classified by \pm contact component, the difference between them being determined by the degree to which $X_{2}$ controls the situation. A group of causative-inchoative verbs, such as 
three-place predicates leave, give, donate, present, involve full control of the situation by $X_{1}$ and inactivity of $X_{2}$. Cf:

(13) *"Your husband has given you this house," Carlos remarked on the day of her arrival

(14) *"How he had left his house to her, and she thought she would stay there, because in spite of everything she had been happy there, most of her memories of the place were good ones."

Both sentences have the same referential characteristics, all components referring to specific objects though they differ in their configuration. In (13) the name of $X_{2}$ follows the name of $Y$ and is accented more prominently, while in (14) the name of $X_{2}$ precedes the name of $Y$ which is under focus.

(13) and (14) are perhaps more prototypical than (5) since they involve one causator who changes the state of $X_{2}$. It should be noted that buy can also express such semantics when used with for, cf. (15), which doesn't imply any activity on the part of $X_{2}$.

(15) *"She had bought the place for him after the divorce, hoping he would enjoy having a home near the lake."

\section{Discussion}

Much research in the linguistic category of possession that has been done by now has been focused on constructions with 's. Significantly less number of works deal with predicative possessive constructions. We hope that this paper will contribute to better understanding of their structure. We took as a basis for our investigation Brinton's conception of predication analysis, which makes it possible to include in the domain of possession a number of verbs and predicative constructions that haven't been properly studied earlier. Brinton's work written within scope of structural semantics and transformational grammar holds that the simplest constructions with stative verbs are basic and the other constructions are formed by adding additional features. We attempted to show basing on the notion of prototypical situation developed within scope of cognitive linguistics that the inverse relationship is also possible. Basic predicative possessive constructions are causative ones and the other types of sentences are formed by omission of semantic features.

The concept of the prototypical situation, as we see it, differs essentially from predication analysis in one important respect. Predication analysis as well as transformational grammar theories are based on the implicit assumption, which perhaps goes back to Zellig Harris's concept of kernel sentences (1957: 335), that basic structures are simpler than those ones derived from them. A kernel sentence is considered to be simple, unmarked in mood, voice and polarity; and various transforms of kernel sentences are derived by adding these features. The prototypical situation concept doesn't involve this simplicity-complexity dichotomy. Prototypical constructions can be simpler or more complex than the non-prototypical ones. The former is the case with the possessive predicative constructions; three-place constructions are prototypical since they reflect the structure of the prototypical situation that comprises three participants, while two-place constructions are less prototypical because one of the participants $(X 2)$ is not named though implied. The sentence *Dennis has a house implies that 
$X 1$ (Dennis) either inherited or bought the house form $X 2$ whose name is omitted due to some stylistic or discourse requirements.

The classification that we suggest comprises the following types of possessive predicative constructions: causative-inchoative, causative-ergessive, causative-continuative, agentiveinchoative, agentive-egressive, agentive-continuative, inchoative, egressive, continuative, stative. Causative sentences in "pure" form cannot be found because causative semantics involves changing of state of $X_{1}$ and $X_{2}$ determined by transference of $Y$ from one possessor to the other one. We failed to find examples of causative-continuative sentences in the Corpus of Contemporary American English as well as in British National Corpus because this semantics, as we presume, contradicts the prototypical situation denoted by possessive predicative constructions.

Predication analysis can be complemented with componential analysis to distinguish between subtypes of these constructions. We used the following semantic features to distinguish between subclasses of causative sentences:

- \pm contact. This feature indicates contact between $X 1$ and $X 2$;

- \pm collective. This feature indicates specific or indefinite reference of $X_{2}$;

- \pm repeated action. This feature indicates a repeated or unique action expressed by the possessive verb;

- \pm initiator. This feature indicates a characteristic of $X_{1}$ by which it is differentiated from $X_{2}$ in causative-inchoative sentences;

- \pm activity. This feature indicates activity or inactivity of $X_{2}$.

We must emphasize the fact that the suggested correlation of possessive predicative constructions is not aimed at rejection of Brinton's conception. The latter may be successfully applied for analysis of some other types of predications, for example those ones used to express the idea of inalienable possession.

\section{Conclusions}

In this paper we attempted to characterize two approaches to the study of linguistic category of possession. The taxonomic approach is based on the principle of isomorphic correlation between linguistic content and form while the restrictive approach licenses the possibility of difference between them; constructions having possessive form can be not possessive in meaning. The two approaches are in no way incompatible, moreover they complement each other. The empirical data obtained by means of the taxonomic approach provide material for investigations within scope of the restrictive approach. Taxonomic and restrictive approaches are correlated as empirical and theoretical levels of investigation of the category of possession.

We conducted distributional analysis of predication semantic features to suggest a novel approach to their correlation and classification of possessive predicative constructions. This approach may be termed predication-componential; main classes of possessive sentences are distinguished by predication semantic features whereas their subclasses are differentiated by semantic features used in componential analysis. 
Contemporary linguistic research is characterized by wide use of achievements of cognitive science. One of them is the notion of the prototypical situation that as we have tried to show allows making graded categorization of possessive constructions distinguishing a variety of their forms.

\section{References}

Börjars, Kersti/Burridge, Kate (2001): Introducing English grammar. New York: Oxford University Press.

Brinton, Laurel (2000): The structure of modern English. Amsterdam: John Benjamins.

Buy-BNC: British National Corpus. www.corpus.byu.edu/bnc/, accessed December 5, 2013.

Carranza, Luz Marina Vásquez (2010): "Cross-linguistic influence evidenced in possessive constructions. A study with an English-Spanish simultaneous bilingual child". Káñina 34/1: 147-167.

Comrie, Bernard (1981): Language universals and linguistic typology. Syntax and morphology. Chicago: University of Chicago Press.

Dixon, Robert (2000): "A typology of causatives. Form, syntax and meaning". In: Dixon, Robert/Aikhenvald, Alexandra (eds.): Changing valency. Case studies in transitivity. New York, Cambridge University Press: 30-83.

Dowty, David (1979): Word meaning and Montague grammar. The semantics of verbs and times in generative semantics and in Montague's PTQ. Dordrecht: Reidel.

Harris, Zellig (1957): "Co-occurrence and transformation in linguistic structure". Language 33/3: 283-340.

Kleiber, George (1990): La semantique de prototype. Categories et sens lexical. Paris: Presses Universitaires de France.

Lehmann, Christian (1991): "Predicate classes and participation". In: Seiler, Hansjakob/Premper, Waldfried (eds.): Partizipation. Das sprachliche Erfassen von Sachverhalten. Tübingen, Narr: 183-239.

Lehmann, Christian ( $\left.{ }^{2} 2002\right)$ : Possession in yucatec maya. Structures - functions - typology. Münster: E-Learning-Academy.

McGregor, William B. (2009): "Introduction". In: McGregor, William B. (ed.): The expression of possession. Berlin, de Gruyter: 1-11.

Merriam-Webster: Dictionary and thesaurus. www.merriam-webster.com/, accessed December 3, 2013.

Premper, Waldfried (1991): "Invitation to participation". In: Seiler, Hansjakob/Premper, Waldfried (eds.): Partizipation. Das sprachliche Erfassen von Sachverhalten. $2^{\text {nd }}$ edition. Tübingen, Narr : 3-12.

Rosch, Eleanor (1975): "Cognitive representations of semantic categories". Journal of Experimental Psychology 104/3: 192-233.

Rosch, Eleanor (1978): "Principles of categorization". In: Rosch Eleonor/Lloyd Barbara (eds.): Cognition and categorization. Hillsdale, Lawrence Erlbaum: 27-48.

Seiler, Hansjakob (1983): Possession as an operational dimension of language. Tübingen: Narr.

Storto, Gianluca (2003): Possessives in context. Issues in the semantics of possessive constructions. Los Angeles: University of California

Taylor, John (2001): Possessives in English. An exploration in cognitive grammar. New York: Oxford University Press.

The corpus of contemporary american English (COCA). www.corpus.byu.edu/coca/, accessed December 5, 2013.

Willemse, Peter/Davidse, Kristine/Heyvaert, Liesbet (2009): "English possessives as reference-point constructions". In: McGregor, William B. (ed.): The expression of possession. Berlin, de Gruyter: 13-50. 
Yatsko, Tatiana/Yatsko, Viatcheslav (2012): "The category of possession. The restrictive approach". In: Book of abstracts. Third International Postgraduate Conference on Language and Cognition (ELC3). Santiago de Compostela: 54-55. www.elc3.elcpostgraduateconference.es/wp-content/uploads/2012/09/Libro-de-abstracts-FINAL.pdf, accessed December 5, 2013. 